Original Research

\title{
Bisphenol A Release from Orthodontic Clear Aligners: An In-Vitro Study
}

Sydney Katras ${ }^{1,}{ }^{*}$, Dejian Ma ${ }^{2}$, Ayman al Dayeh ${ }^{3}$, David Tipton ${ }^{4}$

1. Department of Orthodontics, College of Dentistry, University of Tennessee Health Science Center, Memphis 38163, Tennessee, United States; E-Mail: shkatras@gmail.com

2. Department of Pharmaceutical Sciences, College of Pharmacy, University of Tennessee Health Science Center, Memphis, Tennessee 38163, United States; E-Mail: dma6@uthsc.edu

3. Department Orthodontics, College of Dentistry, University of Tennessee Health Science Center, Memphis 38163, Tennessee, United States; E-Mail: aaldayeh@uthsc.edu

4. Department of Bioscience Research, University of Tennessee Health Science Center, Memphis, Tennessee 38163, United States; E-Mail: biodoc1@aol.com

* Correspondence: Sydney Katras; E-Mail: shkatras@gmail.com

Academic Editor: Eugeniusz Sajewicz

Special Issue: Advanced Dental Materials

Recent Progress in Materials

2021, volume 3, issue 3

doi:10.21926/rpm.2103034
Received: March 31, 2021

Accepted: July 31, 2021

Published: August 12, 2021

\begin{abstract}
Bisphenol A (BPA) is a widely used synthetic compound that has been identified as an endocrine disruptor. It has been linked to adverse health effects such as developmental defects, infertility in both men and women, cardiovascular disease, and obesity. There has been increased interest in BPA's effects on the developing fetus and data has revealed that doses below the presumed safe dose can produce harmful effects. Orthodontic clear aligner therapy is a popular treatment modality that involves the patient wearing sets of plastic aligners up to 22 hours per day for the duration of treatment. The BPA release from these aligners was rarely investigated. The objective of this study was to detect, quantify, and compare the amount of BPA released by 3 popular brands of orthodontic aligners in artificial saliva, artificial gastric fluid, and ethanol. Equal amounts of SmileDirectClub ${ }^{\circledR}$, Invisalign ${ }^{\circledR}$, and Essix $\mathrm{Ace}^{\circledR}$ aligners were placed in sterile glass vials and submerged in $5.5 \mathrm{~mL}$ artificial saliva,
\end{abstract}

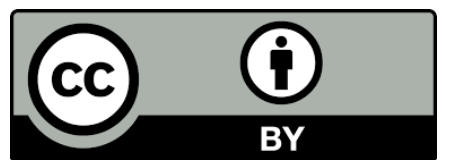

(c) 2021 by the author. This is an open access article distributed under the conditions of the Creative Commons by Attribution License, which permits unrestricted use, distribution, and reproduction in any medium or format, provided the original work is correctly cited. 
artificial gastric fluid, and ethanol. Samples were incubated at $37^{\circ} \mathrm{C}$ and $1 \mathrm{~mL}$ aliquots were removed at various time points. Samples were prepared and analyzed using high performance liquid chromatography tandem mass spectrometry. BPA was released from all three brands of aligners with great variability. Peak BPA concentrations were detected in artificial saliva; Smile Direct Club ${ }^{\circledR}$ produced $5.0 \mathrm{ng} / \mathrm{mL}$ after 20 days, Invisalign ${ }^{\circledR}$ released $3.5 \mathrm{ng} / \mathrm{mL}$ after 24 hours, and Essix Ace ${ }^{\circledR}$ released $6.3 \mathrm{ng} / \mathrm{mL}$ after 10 days of incubation in artificial saliva. There was no significant difference in BPA concentration between the 3 types of aligners in the 3 media. When comparing time points, there was a significant increase of BPA release in the first 24 hours after incubation compared to the baseline $(p<0.001)$. There is potential BPA release from orthodontic aligners. There was no significant difference in the amount of BPA released between the three types of aligners at any time point. The majority of BPA release occurred during the first 24 hours.

\section{Keywords}

Orthodontics; clear aligner therapy; bisphenol A; estrogenicity

\section{Introduction}

Bisphenol A (BPA) is a widely used synthetic organic compound that can act as an endocrine disruptor due to its estrogen-like activity [1]. BPA is a principal ingredient in the production of polycarbonate plastics and epoxy resins, which are used to make food storage containers, children's toys, and dental materials. The primary source of BPA exposure in humans is thought to be through ingestion of food contaminated with BPA that has leached from containers, as well as dental materials [2, 3].

BPA is a known endocrine disruptor; it has been found to bind to estrogen receptors and have estrogenic effects in laboratory studies. Further, BPA can act as an antiestrogen, blocking the estrogenic response by competing with endogenous $17 \beta$ estradiol $[4,5]$. BPA can also directly bind to androgen receptors, and is possibly antiandrogenic, blocking endogenous androgen action [6, 7]. BPA binds to thyroid receptors and has both agonistic and antagonistic effects on thyroid function $[6,8]$. Besides interfering with the actions of hormones [9], BPA increases the risk of cancer, diabetes, heart disease, and hyperactivity in children. It can also produce both male and female infertility [10]. Studies have found that BPA lowers sperm count in workers at the facilities where BPA is in use [11]. It can cause precocious puberty, promote the growth of hormone-dependent tumors, influence metabolic disorders such as polycystic ovarian syndrome, and disrupt glycemic control and increase insulin resistance in type 2 diabetic patients [12].

The first safety standard set by the Environmental Protection Agency in 1988 and adopted by the Food and Drug Administration as a reference dose for BPA was $50 \mu \mathrm{g} / \mathrm{kg} \mathrm{BW} /$ day [13]. It remained at that level until 2015, when the tolerable daily intake of BPA was reduced to $4 \mu \mathrm{g} / \mathrm{kg} B W /$ day [14]. There is evidence that BPA may exert non-monotonic dose-responses, which indicates that even low doses (nanomolar range) of BPA may induce adverse effects although these levels are assumed to be safe. Moreover, the activity level lies within a range that is under the detection limit of most analytical methods. 
Clear plastic aligners are a popular form of orthodontic therapy to correct dental crowding. It involves patients wearing sets of aligners for $\sim 22 \mathrm{hrs}$ per day for the course of the treatment. The number of prescribed aligners varies and is dependent on the amount of dental crowding and case complexity. Many cases require over 60 sets of maxillary and mandibular aligners that are changed on weekly or biweekly basis. While these aligner materials are advertised as BPA-free, few studies measured and compared the potential BPA release from these materials.

Solid Phase Extraction (SPE) followed by high performance liquid chromatography/ tandem mass spectrometry (LC-MS/MS) provide a highly sensitive method to detect and quantify BPA. The objective of this study is to investigate the BPA release from three types of commercially available aligners' material: Invisalign ${ }^{\circledR}$, SmileDirectClub ${ }^{\circledR}$, and Essix Ace ${ }^{\circledR}$ plastic using SPE followed by LCMS/MS. The null hypothesis is there is no difference in the amount of BPA released from the three aligners.

\section{Materials and Methods}

\subsection{Materials}

\subsubsection{Orthodontic Clear Aligner Materials}

Unused Invisalign ${ }^{\circledR}$ and SmileDirectClub ${ }^{\circledR}$ clear aligners (Align Technology, Santa Clara, CA and SmileDirectClub, Nashville, TN, respectively) were donated by patients. The Essix Ace ${ }^{\circledR}$ plastic for fabrication of in-house aligners was obtained directly from the manufacturer (Dentsply Sirona, York, PA). The .035" Essix Ace ${ }^{\circledR}$ aligners were thermoformed according to the manufacturers' instructions with a Ministar ${ }^{\circledR}$ vacuum thermoforming system (Model SN 20323, Scheu-Dental GmbH, Iserlohn, Germany) on 3D printed casts. The casts were printed using FormLabs Form ${ }^{\circledR}$ printer (FormLabs, Somerville, MA) and cured according to the manufacturer's recommendations.

\subsubsection{BPA Release Experiment}

All chemical components for artificial saliva, artificial gastric fluid, and ethanol were purchased directly from Sigma Aldrich (MilliporeSigma, Munich, Germany).

\subsubsection{Calibration Standards and Sample Preparation for LC-MS/MS}

All mobile phase solvents were purchased from Fisher-Scientific (Pittsburgh, PA, USA). Milli-Q water was used for aqueous mobile phase. BPA and BPA- $d_{16}$ were purchased from Millipore-Sigma for use as external and internal standards, respectively (Sigma-Aldrich, St. Louis, MO).

\subsection{BPA Release Experiment}

Artificial saliva was synthesized by dissolving the constituent chemical components in water. Briefly, $896 \mathrm{mg} \mathrm{KCl}, 888 \mathrm{mg} \mathrm{NaHPO}_{4}, 420 \mathrm{mg} \mathrm{NaHCO} 3,298 \mathrm{mg} \mathrm{NaCl}, 1.8 \mathrm{mg} \mathrm{NaOH}$, and $15 \mathrm{mg}$ uric acid were dissolved in $1 \mathrm{~L}$ deionized water and held at room temperature until use. Artificial gastric fluid was produced by adding $\mathrm{HCl}$ to normal saline solution until a $\mathrm{pH}$ of 1.2 was reached. 200-proof pure ethyl alcohol was used for the ethanol samples. Each of the three types of aligners were cut into sections of $35.0 \pm 1.0 \mathrm{mg}$. A third unbiased party randomized the aligners' sections into glass vials 
containing $5.5 \mathrm{ml}$ of artificial saliva $(\mathrm{n}=8), 5.5 \mathrm{ml}$ of artificial gastric fluid $(\mathrm{n}=3)$ and $5.5 \mathrm{ml}$ of pure ethanol $(n=3)$ each. The investigators that collected the samples and performed the LC-MS/MS measurements were blinded to the aligner material in each vial. $1.0 \mathrm{~mL}$ aliquots of artificial saliva $(n=3)$, artificial gastric fluid $(n=3)$, and ethyl alcohol $(n=3)$ were removed from the $5.5 \mathrm{ml}$ stock solutions to establish baseline BPA concentration (TO). The vials were incubated in a water bath at $37.5^{\circ} \mathrm{C}$. 1.0mL aliquots were removed at $24 \mathrm{hrs}$ (T1), 48hrs (T2), 6 days (T6) 10 days (T10) and20 days (T20). Samples were sealed and stored at $-80^{\circ} \mathrm{C}$ until analysis.

\subsection{Sample Preparation and LC-MS/MS Measurement}

Stock solutions of BPA and BPA- $\mathrm{d}_{16}(10 \mathrm{mM})$ were prepared in methanol. Milli-Q water was used in all subsequent dilution to make calibration standards. All the samples (except the samples extracted using ethanol) were processed using solid phase extraction (SPE). The purpose of SPE is to remove salt from the sample solution to minimize the suppression of the target ion signal strength. Briefly, Oasis HLB 3cc cartridge (Waters, Milford, MA) was conditioned with $2 \times 2 \mathrm{~mL}$ methanol, then equilibrated with $2 \times 2 \mathrm{~mL}$ Milli-Q water. After that, $0.5 \mathrm{~mL}$ sample solution was loaded and subsequently washed with $2 \times 2 \mathrm{~mL}$ water, and finally BPA was eluted with $2 \times 1 \mathrm{~mL}$ methanol. The SPE eluate was dried down under a gentle stream of nitrogen gas flow and stored under $-20^{\circ} \mathrm{C}$. For samples extracted using ethanol, a $0.5 \mathrm{~mL}$ sample was directly evaporated to dryness under nitrogen without SPE procedure. For LC-MS/MS measurement, each sample was reconstituted in $100 \mu \mathrm{L}$ internal standard (BPA- $\mathrm{d}_{16}$ ) water solution and $80 \mu \mathrm{L}$ was then transferred to a 96-well plate. A sample aliquot $(1 \mu \mathrm{L})$ was injected for LC-MS/MS analysis and the amount of BPA released from each sample at designated timepoints was quantified.

The LC-MS/MS system used for BPA quantification was a Sciex (Framingham, MA) 5500 triple quadrupole mass spectrometer, equipped with a Turboionspray ${ }^{\mathrm{TM}}$ (electrospray ionization, ESI) interface, and coupled with a Shimadzu (Columbia, MD) Nexera XR HPLC system and SIL-20ACXR autosampler. Separation of analytes was carried out using an Eclipse Plus C18 column of $50 \times 2.1$ $\mathrm{mm}$ i.d., and $5 \mu \mathrm{m}$ particle size (Agilent Technologies, Santa Clara, CA). The mobile phase consists of Milli-Q water with $5 \%$ methanol as mobile phase $A$, and methanol as $B$. The combined flow rate was $0.5 \mathrm{~mL} / \mathrm{min}$. A gradient time program was applied as following: 0-1 min 20\% B; $1-1.5 \mathrm{~min} 20-90 \% \mathrm{~B}$; 1.5-2.8 $\mathrm{min} 90 \% \mathrm{~B} ; 2.8-2.9 \mathrm{~min} 90-20 \% \mathrm{~B} ; 2.9-3.0 \mathrm{~min} 20 \% \mathrm{~B}$, and the time program stopped at 3.0 min. Total run time was 4.5 minutes with an extra 1.5 min equilibrate time before each run with $20 \%$ mobile phase B. The retention time was 2.45 min for both BPA and internal standard (BPA- $d_{16}$ ). A switching valve directed eluent to MS between 2.1 and 2.8 min during the 3 min time program. The flow was directed to waste bottle before $2.1 \mathrm{~min}$ and after $2.8 \mathrm{~min}$ to avoid unnecessary contamination to the MS ion source and analyzer.

Negative ionization mode was used with typical ion source parameters as following: TurbolonSpray (IS) voltage $-4.5 \mathrm{kV}$, entrance potential (EP) -10 V, declustering potential (DP) $-135 \mathrm{~V}$, collision energy (CE) $-30 \mathrm{eV}$ for BPA, $-36 \mathrm{eV}$ for BPA- $d_{16}$, and collision cell exit potential (CXP) $-7 \mathrm{eV}$ for BPA, $-9 \mathrm{eV}$ for BPA- $d_{16}$. The channel electron multiplier (CEM) was $2100 \mathrm{~V}$, and source temperature was set at $600^{\circ} \mathrm{C}$. Dwell time was $200 \mathrm{~ms}$. Curtain gas was set at 20 PSI. Both Gas 1 (nebulizer gas) and Gas 2 (desolvation gas) were 50 PSI. CAD (collision gas) was 8 PSI. Multiple reaction-monitoring (MRM) in negative mode was used for quantification of BPA (227.1/133.1) and BPA- $_{16}(241.1 / 142.1)$. Note that the deuterium atoms of the two hydroxy groups in BPA- $d_{16}$ are 
exchangeable with the solvent once in methanol solution, therefore the precursor mass for BPA-d $d_{16}$ in negative mode was 241.1 Da instead of 243.1 Da. Measurements were performed in duplicate and the results were averaged. The software program Analyst (Version 1.6.3) and MultiQuant (Version 3.0.2) were used to process the analytical data.

\subsection{Statistical Analysis}

Kruskal Wallis test was used to assess the difference in the amount of BPA release from the Invisalign ${ }^{\circledR}$, SmileDirectClub $^{\circledR}$, and Essix Ace ${ }^{\circledR}$. Friedman test was used to compare the amounts of BPA released between various time points. Statistical significance was set at 0.05 . Statistical analysis was performed using IBM ${ }^{\circledR}$ SPSS Statistics (IBM, Armonk, NY).

\section{Results}

SmileDirectClub ${ }^{\circledast}$ aligners showed the least amount of BPA release in ethanol, followed by artificial gastric fluid, and the highest amount of BPA release in artificial saliva, with $5.0 \mathrm{ng} / \mathrm{mL}$ detected at $T_{F}$ (Figure $1 A$ ). Peak BPA concentration in artificial gastric fluid occurred at $T_{6}$, with a value of $3.1 \mathrm{ng} / \mathrm{mL}$. Invisalign ${ }^{\circledR}$ (Figure $1 \mathrm{~B}$ ) showed the highest release of BPA in ethanol at $T_{10}$ $(9.2 \mathrm{ng} / \mathrm{mL})$. The highest BPA release in artificial saliva occurred at $T_{6}$ with a value of $3.5 \mathrm{ng} / \mathrm{mL}$. Very little BPA was released in the artificial gastric fluid samples. The highest release of BPA in the Essix Ace $^{\circledR}$ aligner group (Figure $1 \mathrm{C}$ ) was seen in artificial saliva with $6.3 \mathrm{ng} / \mathrm{mL}$ at $\mathrm{T}_{10}$. Peak BPA release in artificial gastric fluid occurred at $T_{1}$, with a value of $3.5 \mathrm{ng} / \mathrm{mL}$. No significant difference in BPA concentration was found between the 3 types of aligners in the 3 media at each of the time points ( $p>0.28$, Kruskal Wallis test). When comparing time points, the difference in BPA concentration was significant $(p<0.001$, Friedman test). Post hoc analysis revealed that this difference was due to the higher BPA concentration at $T_{1}$ compared to $T_{0}$. No difference was found between the remaining timepoints. 


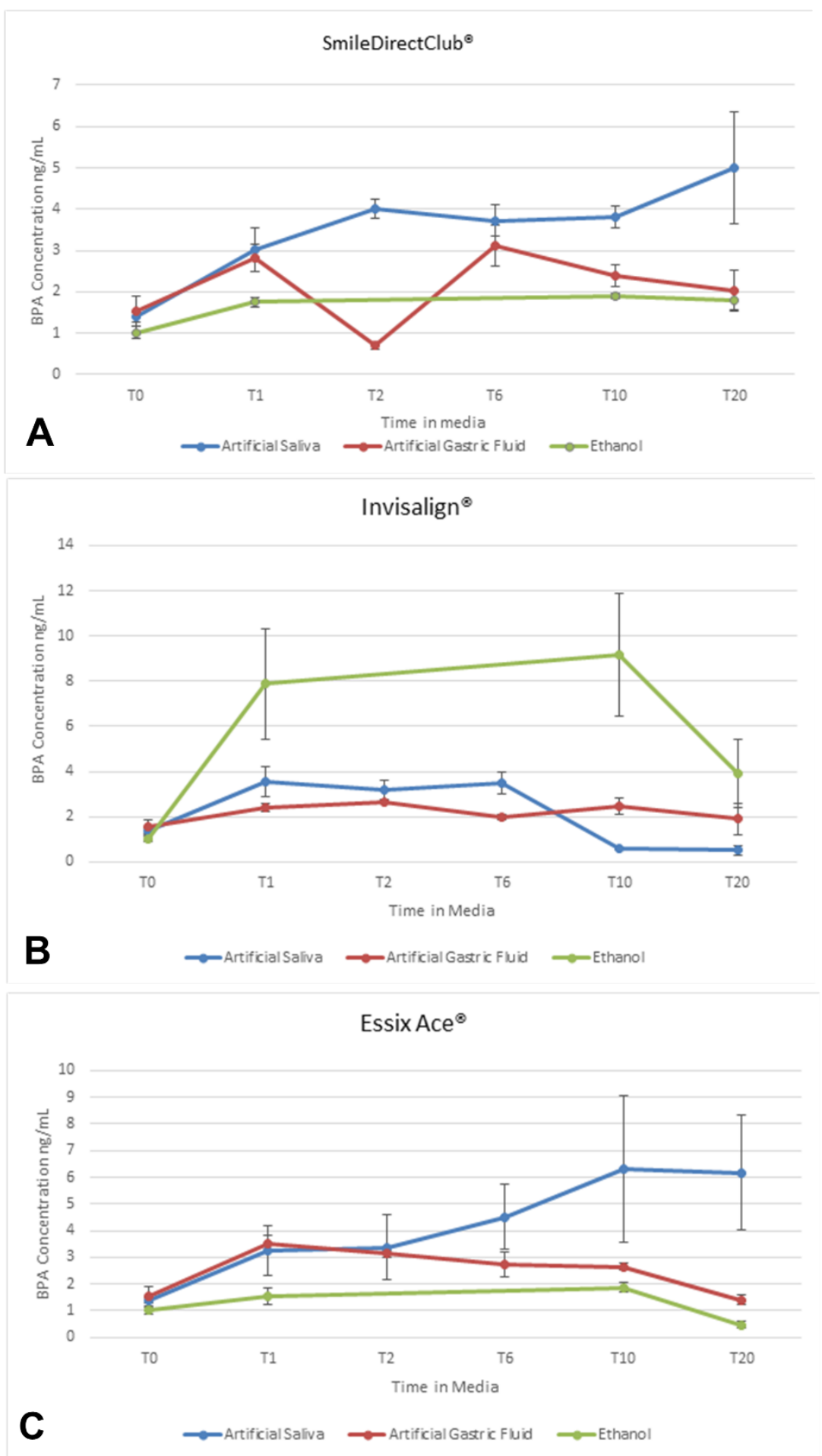

Figure 1 A SmileDirectClub ${ }^{\circledR}$ BPA concentration in artificial saliva, artificial gastric fluid and ethanol after $24 \mathrm{hrs}\left(T_{1}\right), 48 \mathrm{hrs}\left(T_{2}\right), 6$ days $\left(T_{6}\right), 10$ days $\left(T_{10}\right)$, and 20 days $\left(T_{20}\right)$. Samples were analyzed using LC-MS/MS. B Invisalign ${ }^{\circledR}$ BPA concentration in artificial saliva, artificial gastric fluid and ethanol after $24 \mathrm{hrs}\left(T_{1}\right)$, 48hrs $\left(T_{2}\right), 6$ days $\left(T_{6}\right), 10$ days $\left(T_{10}\right)$, and 20 days $\left(T_{20}\right)$. Samples were analyzed using LC-MS/MS. C Essix Ace ${ }^{\circledR}$ BPA concentration in artificial saliva, artificial gastric fluid and ethanol after $24 \mathrm{hrs}\left(\mathrm{T}_{1}\right)$, 48hrs $\left(T_{2}\right), 6$ days $\left(T_{6}\right), 10$ days $\left(T_{10}\right)$, and 20 days $\left(T_{20}\right)$. Samples were analyzed using LC-MS/MS. 


\section{Discussion}

In this study we report on BPA release from three types of orthodontic aligners in three media: artificial saliva, artificial gastric fluid and ethanol. Although the three types of aligners are advertised as BPA-free, small amount of BPA was detected. On average, the aligners in this experiment released 3.6ng/ml (range 1.4-6.3) of BPA in artificial saliva with no difference between the three materials tested. Patients typically wear each set of maxillary and mandibular aligners for 1-2 weeks. The number of aligners needed vary by severity of the case, with most of the comprehensive cases requiring $>60$ sets of aligners. The average weight of one set of aligners is $\sim 3.6$ grams. Thus, according to our results, each set of aligners could potentially release $\sim 1.8 \mu \mathrm{g}$ (1851 ng) of BPA. Our results are lower than those reported by Kotyk et al [15], who reported, using gas chromatography/mass spectroscopy, $7.6 \mu \mathrm{g}$ of BPA released from $1 \mathrm{~g}$ of Essix Ace ${ }^{\circledR}$ with great variability. They also investigated BPA release from Invisalign, reporting no-detectable value. While differences in sample preparation and the detection methodology between the two studies make comparison difficult, it suggests that more standardized studies are needed to assess BPA release from aligners. In this study we utilized LC-MS/ MS, while Kotyk et al used gas chromatography/mass spectroscopy.

In 2015, the European Food Safety Authority (EFSA) updated and reduced the threshold value for BPA intake to $4 \mu \mathrm{g} / \mathrm{kg} \mathrm{BW} /$ day after conducting an exposure assessment. According to that report [12] the average daily intake of BPA amounted to $126 \mathrm{ng} / \mathrm{kg}$ BW/day among adults in Europe through diet, which is well below the threshold value for safety. Thus, the BPA released from aligners is well below the safety threshold established by the EFSA. However, a prevailing concern regarding BPA exposure is its ability to bind to the estrogen receptors $\alpha(E R \alpha)$ and $\beta$ (ER $\beta$ ), through which this endocrine-active substance may affect humans at doses below the presumably safe tolerable daily intake. Several studies have suggested an adverse endocrine disruptive effect by BPA at doses as low as $0.025-0.200 \mu \mathrm{g} / \mathrm{kg} / \mathrm{day}$, such as a decrease in daily sperm production and fertility in males at a dose of $0.2 \mu \mathrm{g} / \mathrm{kg} / \mathrm{day}$ [13] stimulation of mammary gland development at 0.025-0.250 $\mu \mathrm{g} / \mathrm{kg} /$ day $[14,16]$ and a decrease in antioxidant enzymes at $0.2 \mu \mathrm{g} / \mathrm{kg} /$ day [17]. In addition to these multi-system health effects being linked to BPA, there is evidence of transcription of proliferation and differentiation-related genes in response to low-dose BPA in activated ER $\beta$ in oral keratinocytes, which are the first targets of BPA by oral intake [18] showed a sublingual absorption of BPA besides typical digestion, which shows that BPA can diffuse through oral mucosal tissues.

Aligners are typically placed in the oral cavity for 22 hours per day for 1-2 weeks to achieve gradual tooth movement. Once the aligner is passive, the patient moves to a new set of aligners. Aligners in the oral cavity undergo wear, cracking and distortion [19], which can potentially lead to BPA release and swallowing of small particles. The presence of BPA in the saliva of patient wearing either Hawley or Essix Ace retainer was investigated by Raghavan et al. [20]. They reported higher BPA in the saliva of the patients wearing the Essix Ace ${ }^{\circledR}$ retainer 1 hour and 1 week after using the retainers, the values sharply decreased afterwards. While comparing the values reported to those in our study is complicated by the differences in methodology, their findings suggest that BPA released from aligners is absorbed systemically. Eliades et. al. [21] reported on the in-vitro cytotoxicity and estrogenicity of Invisalign ${ }^{\circledR}$ appliances on cultured human gingival fibroblasts. Although their results show minimal effects of Invisalign, the level of BPA used in their study was 
not reported. Future studies will need to assess the effects of BPA in dose dependent manner and under in vivo conditions that closely resemble the clinical application of the aligners.

The three types of aligners chosen for use in this study were Invisalign ${ }^{\circledR}$, which is probably the most widely known brand of clear aligner, SmileDirectClub ${ }^{\circledR}$, a popular direct-to-consumer clear aligner brand, and Essix Ace ${ }^{\circledR}$, which is commonly used to provide in-house clear aligner therapy. All three types are made with thermoformed plastic on digitally printed resin models and delivered to the patient, who places them in the oral cavity. The three types of media chosen for this experiment were artificial saliva, artificial gastric fluid, and pure ethanol. Clear aligners are subjected to heavy masticatory forces increasing the likelihood that small particles of the plastic are accidentally ingested. We wanted to see if contact with artificial gastric fluid and the highly acidic environment influenced BPA release. Interestingly, there was less BPA released in artificial gastric fluid than in artificial saliva, indicating that there could be a positive correlation between acidity and stability. Ethanol was added to the media set because BPA is soluble in organic solvents and we wanted to determine whether consumption of alcoholic beverages can affect BPA release from aligners. Clinicians instruct their patients not to eat or drink with the aligners in their mouths but compliance varies widely. While a trend for higher BPA release was seen in Invisalign ${ }^{\circledR}$ group, the differences did not reach statistical significance.

There is increasing interest in the adverse effects of fetal exposure to BPA due to its ability to pass through the placenta from mother to baby, and the low endogenous concentration of UDPglucuronosyltransferase (UGT) in a fetus [1]. Liver UGT activities have an important effect on the removal and detoxification of BPA. UGT in the human fetal liver is present at a concentration fivefold lower than in the adult liver, posing a much higher risk of exposure [1]. In addition, BPA that is removed via fetal UGT is excreted in the urine, increasing the concentration of BPA in amniotic fluid and prolonging exposure [22]. The highest concentrations of BPA have been recorded in the placenta and fetus, with values ranging from 1 to $104 \mathrm{ng}$ per gram of tissue [23]. Fetal exposure to BPA has been linked to obesity, behavioral and mood disorders, cognitive impairment, and sexspecific alterations to the reproductive system [24, 25]. Because women of child-bearing age constitute a major user of clear aligners [26, 27], extra precautions should be taken to reduce exposure to BPA. One of the interesting findings of this study was that most of the BPA release happened during the first 24 hours following incubation. This is comparable to Raghavan et al (2017), who reported sharp increase of BPA in saliva 1 hour after the patient wearing the Essix Ace ${ }^{\circledR}$ retainer. While the limited time points in both studies prevent definitive conclusion, they suggest that most of the BPA release occur within the first 24 hours of wearing the aligners. Thus, a simple activity such as rinsing the aligners or soaking them in deionized water before wearing could significantly decrease exposure.

Our study suffered several limitations, and the clinical implications need to be interpreted with care. First, the study was done in vitro. In the oral cavity, constant flow of the saliva might help increase the elimination rate of BPA, limiting its clinical impact. Nonetheless, the presence of BPA in orthodontic aligners suggests that further studies are needed to determine their biologic impact especially in vulnerable population such as pregnant females. Another limitation is the extended time intervals for BPA detection. Initially, we expected that the BPA release will be extended over period of days and the time points were designed accordingly. Surprisingly, most of the BPA release was seen at the first time point ( $24 \mathrm{hrs}$ ). Future studies should assess the BPA release on hourly rather than daily basis as the acute release might result in more impact on the body. Our study was 
further affected by our limited knowledge of the plastic fabrication and, except for the in house aligners, the aligners' fabrication. Careful observation of the fabrication process will help to determine whether reduction of the BPA content in the aligners are feasible. We attempted to investigate the products as received by the patient to determine whether the products are clinically safe. Future studies will need to collaborate with the manufacturers to determine the effects of various manufacturing parameters on the final BPA release from the aligners.

\section{Conclusions}

- There is potential BPA release from the three types of orthodontic aligners investigated

- The amount of BPA released is well below the established safety levels for adult patients

- There was no significant difference in the amount of BPA released between the three sets of aligners in each of the three media.

- The majority of BPA release occurred during the first 24 hours of embedding the aligners

\section{Acknowledgments}

The authors would like to acknowledge NIH (National Institutes of Health) S10 grant 1S100D016226-01A1 for the SCIEX 5500 LC-MS instrument.

\section{Additional Materials}

The following additional materials are uploaded at the page of this paper.

1.Table I: BPA release from SmileDirectClub ${ }^{\circledR}$, Invisalign ${ }^{\circledR}$, and Essix Ace ${ }^{\circledR}$ in artificial saliva.

2. Table II: BPA release from SmileDirectClub ${ }^{\circledR}$, Invisalign ${ }^{\circledR}$, and Essix Ace ${ }^{\circledR}$ in artificial gastric fluid.

3. Table III: Mean BPA levels $(\mathrm{ng} / \mathrm{mL}$ ) released from orthodontic clear aligners at different time points in ethanol.

4. Figure IIA: BPA release from SmileDirectClub ${ }^{\circledR}$, Invisalign ${ }^{\circledR}$, and Essix Ace ${ }^{\circledR}$ in artificial saliva.

5. Figure IIB: BPA release from SmileDirectClub ${ }^{\circledR}$, Invisalign ${ }^{\circledR}$, and Essix Ace ${ }^{\circledR}$ in artificial gastric fluid.

6. Figure IIC: Mean BPA levels $(\mathrm{ng} / \mathrm{mL}$ ) released from orthodontic clear aligners at different time points in ethanol.

\section{Author Contributions}

Dr. Katras conceived and designed the experiment, performed the experiment, and collected the samples. Dr. Ma prepared the samples, conducted the liquid chromatography tandem mass spectroscopy measurements, and wrote the sample preparation and LC-MS/MS section of the paper. Drs. al Dayeh and Katras performed statistical analysis, interpreted the results, created the graphs and figures, and wrote the manuscript, with the exception of Dr. Ma's contribution. Dr. Tipton provided guidance and insight throughout all stages of the experiment and writing of the manuscript. 


\section{Funding}

This study was supported by internal research funding allocated to the Graduate Program in the Department of Orthodontics at the University of Tennessee Health Science Center.

\section{Competing Interests}

The authors have declared that no competing interests exist.

\section{References}

1. Kang JH, Kondo F, Katayama Y. Human exposure to bisphenol A. Toxicology. 2006; 226:79-89.

2. Han DH, Kim MJ, Jun EJ, Kim JB. Salivary bisphenol-a levels due to dental sealant/resin: A casecontrol study in Korean children. J Korean Med Sci. 2012; 27: 1098-1104.

3. Kloukos D, Pandis N, Eliades T. Bisphenol-A and residual monomer leaching from orthodontic adhesive resins and polycarbonate brackets: A systematic review. Am J Orthod Dentofacial Orthop. 2013; 143: S104-S112.e2.

4. Rochester JR. Bisphenol A and human health: A review of the literature. Reprod Toxicol. 2013; 42: 132-155.

5. Dodds EC, Lawson W. Synthetic estrogenic agents without the phenanthrene nucleus. Nature. 1936; 137: 996.

6. Wetherill YB, Akingbemi BT, Kanno J, McLachlan JA, Nadal A, Sonnenschein C, et al. In vitro molecular mechanisms of bisphenol A action. Reprod Toxicol. 2007; 24: 178-198.

7. Sohoni P, Sumpter JP. Several environmental oestrogens are also anti-androgens. J Endocrinol. 1998; 158: 327-339.

8. Moriyama K, Tagami T, Akamizu T, Usui T, Saijo M, Kanamoto N, et al. Thyroid hormone action is disrupted by bisphenol $A$ as an antagonist. J Clin Endocrinol Metab. 2002; 87: 5185-5190.

9. Liu XQ, Miao MH, Zhou ZJ, Gao E, Chen JP, Wang JT, et al. Exposure to bisphenol-A and reproductive hormones among male adults. Environ Toxicol Pharmacol. 2015; 39: 934-941.

10. Ma Y, Liu HH, Wu JX, Yuan L, Wang YQ, Du XD, et al. The adverse health effects of bisphenol A and related toxicity mechanisms. Environ Res. 2019; 176: 108575.

11. Rubin BS. Bisphenol A: An endocrine disruptor with widespread exposure and multiple effects. J Steroid Biochem Mol Biol. 2011; 127: 27-34.

12. EFSA, CEF. Scientific opinion on the risks to public health related to the presence of Bisphenol A (bpa) in foodstuffs. EFSA J. 2015; 13: 3978.

13. vom Saal FS, Welshons WV. Evidence that bisphenol A (BPA) can be accurately measured without contamination in human serum and urine, and that BPA causes numerous hazards from multiple routes of exposure. Mol Cell Endocrinol. 2014; 398: 101-113.

14. Markey CM, Wadia PR, Rubin BS, Sonnenschein C, Soto AM. Long-term effects of fetal exposure to low doses of the xenoestrogen bisphenol-A in the female mouse genital tract. Biol Reprod. 2005; 72: 1344-1351.

15. Kotyk MW, Wiltshire WA. An investigation into bisphenol-a leaching from orthodontic materials. Angle Orthod. 2014; 84: 516-520. 
16. Muñoz-de-Toro M, Markey CM, Wadia PR, Luque EH, Rubin BS, Sonnenschein C, et al. Perinatal exposure to bisphenol-A alters peripubertal mammary gland development in mice. Endocrinology. 2005; 146: 4138-4147.

17. Nelson W, Adu-Gyamfi EA, Czika A, Wang YX, Ding YB. Bisphenol A-induced mechanistic impairment of decidualization. Mol Reprod Dev. 2020; 87: 837-842.

18. Gayrard V, Lacroix MZ, Collet SH, Viguie C, Bousquet-Melou A, Toutain PL, et al. High bioavailability of Bisphenol A from sublingual exposure. Environ Health Perspect. 2013; 121: 951-956

19. Schuster S, Eliades G, Zinelis S, Eliades TE, Bradley TG. Structural conformation and leaching from in vitro aged and retrieved Invisalign appliances. Am J Orthod Dentofacial Orthop. 2004; 126:725-728.

20. Raghavan AS, Sathyanarayana HP, Kailasam V, Padmanabhan S. Comparative evaluation of salivary bisphenol A levels in patients wearing vacuum-formed and Hawley retainers: An in-vivo study. Am J Orthod Dentofacial Orthop. 2017; 151: 471-476.

21. Eliades $T$, Pratsinis $H$, Athanasiou AE, Eliades $G$, Kletsas D. Cytotoxicity and estrogenicity of Invisalign appliances. Am J Orthod Dentofacial Orthop. 2009; 136: 100-103.

22. Kolatorova L, Duskova M, Vitku J, Starka L. Prenatal exposure to bisphenols and parabens and impacts on human physiology. Physiol Res. 2017; 66: S305-S315.

23. Jalal N, Surendranath AR, Pathak JL, Yu S, Chung CY. Bisphenol A (BPA) the mighty and the mutagenic. Toxicol Rep. 2018; 5: 76-84.

24. Hoepner LA, Whyatt RM, Widen EM, Hassoun A, Oberfield SE, Mueller NT, et al. Bisphenol A and adiposity in an inner-city birth cohort. Environ Health Perspect. 2016; 124: 1644-1650

25. Pan R, Wang CF, Shi R, Zhang Y, Wang YW, Cai C, et al. Prenatal Bisphenol A exposure and early childhood neurodevelopment in Shandong, China. Int J Hyg Environ Health. 2019; 222: 896-902.

26. Azaripour A, Weusmann J, Mahmoodi B, Peppas D, Gerhold-Ay A, Van Noorden CJ, et al. Braces versus Invisalignâ: Gingival parameters and patients' satisfaction during treatment: A crosssectional study. BMC Oral Health. 2015; 15: 1-5.

27. Meier B, Wiemer K, Miethke R. Invisalign ${ }^{\circledR}$-patient profiling. Analysis of a prospective survey. J Orofac Orthop. 2003; 64: 352-358.

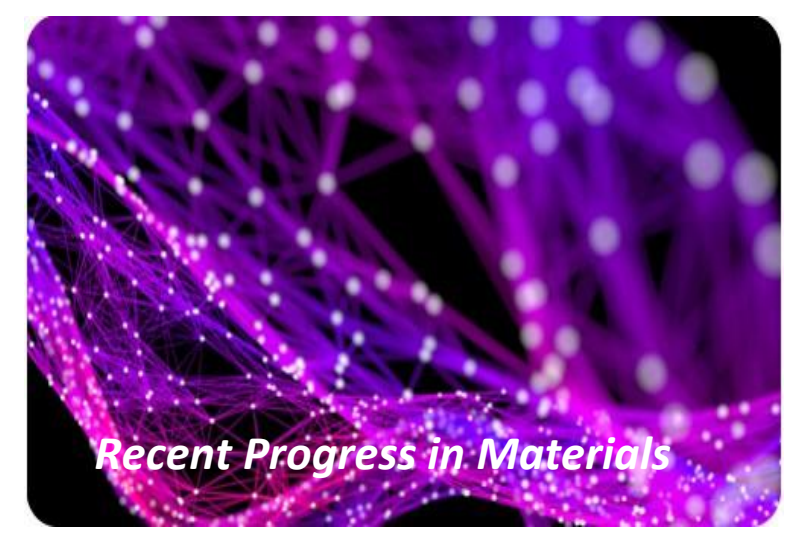

Enjoy Recent Progress in Materials by:

1. Submitting a manuscript

2. Joining in volunteer reviewer bank

3. Joining Editorial Board

4. Guest editing a special issue

For more details, please visit:

http://www.lidsen.com/journals/rpm 